
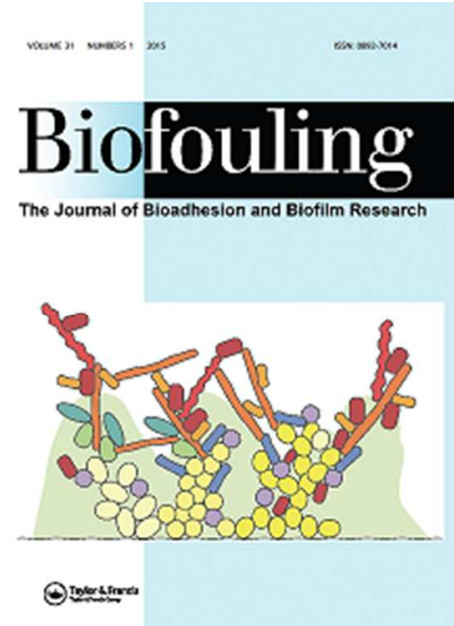

\title{
Biofilm responses to oxidative stress
}

\begin{tabular}{|r|l|}
\hline Journal: & Biofouling \\
\hline Manuscript ID & GBIF-2015-0213.R2 \\
\hline Manuscript Type: & Mini Review \\
\hline Keywords: & $\begin{array}{l}\text { biofilm, oxidative stress, quorum sensing, polysaccharide production, } \\
\text { heterogeneity }\end{array}$ \\
\hline \multicolumn{2}{|c}{} \\
\hline
\end{tabular}

SCHOLARONE ${ }^{m}$

Manuscripts 


\section{Biofilm responses to oxidative stress}

10

11

12

2 Michela Gambino, Francesca Cappitelli*

3 Department of Food, Environmental and Nutrition Sciences, Università degli Studi di Milano,

4 via Celoria 2, 20133 Milano, Italy

5 * corresponding author: Francesca Cappitelli, Department of Food, Environmental and

6 Nutrition Sciences, Università degli Studi di Milano, Via Celoria 2, 20133 Milano, Italy. E-

7 mail: francesca.cappitelli@unimi.it.

8

9 


\section{Abstract}

11 Biofilms constitute the predominant microbial style of life in natural and engineered

12 ecosystems. Facing harsh environmental conditions, microorganisms accumulate reactive

13 oxygen species (ROS), potentially encountering a dangerous condition called oxidative stress. While high levels of oxidative stress are toxic, low levels act as a cue, triggering bacteria to activate effective scavenging mechanisms or to shift metabolic pathways. Although a

16 complex and fragmentary picture results from our current knowledge of pathways activated in response to oxidative stress, three main responses are shown to be central: the existence of 18 common regulators, the production of extracellular polymeric substances and biofilm 19 heterogeneity. An investigation into mechanisms activated by biofilm in response to different 20 oxidative stress levels could have important consequences from ecological and economic 21 points of view, and could be exploited to propose alternative strategies to control microbial 22 virulence and deterioration.

\section{Keywords}

25 biofilm, oxidative stress, quorum sensing, polysaccharide production, heterogeneity 26 27 


\section{Biofilms}

29 The formation of biofilms - microbial communities embedded in a self-produced polymeric matrix attached to a surface- is an ancient and universal trait that enables microorganisms to develop coordinated architectural and survival strategies (Hall-Stoodley et al. 2004; Vlamakis et al. 2013). It is now largely accepted that biofilms constitute the predominant style of microbial life in natural and engineered ecosystems (Mc Dougald et al. 2011; Villa \& Cappitelli 2013). Indeed, biofilm cells express specific phenotype traits that confer adaptability to environmental change (Stewart et al. 2008) and higher resistance to adverse conditions, such as limited nutrient availability, desiccation, low $\mathrm{pH}$ and predation (Rinaudi \& Giordano 2010). The biofilm structure, its surface adhesion and the polymeric matrix provide cells with a high nutrient and water concentration and a suitable environment for signalling pathways, genetic material exchange, metabolite and enzyme interaction (Davey \& O'Toole 2000).

Biofilms can colonize both biotic and abiotic surfaces, causing beneficial and/or detrimental effects to the environment, industry and human health (Costerton et al. 1987). For example, biofilm features are beneficially exploited in wastewater treatment plants (Nicolella 2000), bioremediation (Dash et al. 2013; Wu et al. 2015), biomaterial production and plant growth promotion (Davey \& O’Toole 2000; Rudrappa et al. 2008; Rinaudi \& Giordano 2010). Biofilms are also important in the marine environment where they can modulate the metamorphosis and/or settlement of invertebrate larvae and algal spores through diffusible or contact-mediated signals (Hadfield 2011; Shikuma et al. 2014; Thompson et al. 2015). The presence of biofilm on a host surface also modulates the host's access to nutrients, light, oxygen and toxins (Wahl et al. 2012). Nevertheless, biofilm can also be destructive, causing chronic infection in humans (Bjarnsholt et al. 2013), parasitism in animals and plants (Rinaudi \& Giordano 2010), biodeterioration in engineered systems and artwork (Cappitelli et 

al. 2006), fouling of food-processing equipment (Villa et al. 2012a; Cappitelli et al. 2014) and wastewater treatment plants (Polo et al. 2014). In addition, the presence of biofilms on surfaces can modulate the attachment of macrofoulers (like plants and animals) (Clare et al. 1992). Indeed, marine organisms that maintain a foul-free surface are the main candidates for natural product antifoulants (Clare et al., 1996). Biofilm removal is usually carried out using either biocides or mechanical methods, but a complete and efficient eradication is often difficult (Bruellhoff et al. 2010; Villa et al. 2012c). Eradication problems arise because cells living in biofilm are less sensitive to antimicrobial agents than planktonic bacteria (Mah et al. 2003). In recent years, much effort has been put into addressing the development of preventive strategies that can be used to disarm microorganisms without killing them (Cegelski et al. 2008), eg targeting the early adhesion phase or interfering with cell-to-cell communication (Villa et al. 2010; Bai \& Rai 2011; Villa et al. 2011).

\section{Reactive oxygen species}

Reactive oxygen species (ROS) are chemically reactive molecules produced in aerobic conditions as by-products of several metabolic processes. Molecular oxygen $\left(\mathrm{O}_{2}\right)$ is a small, nonpolar molecule that diffuses easily across biological membranes (Ligeza et al. 1998). Nevertheless, $\mathrm{O}_{2}$ reacts poorly with cellular biomolecules. Its reactivity derives from the formation of ROS (Gerschman et al. 1954), which results from the addition of consecutive electrons to $\mathrm{O}_{2}$, generating the superoxide $\left(\mathrm{O}_{2}{ }^{-}\right)$, hydrogen peroxide $\left(\mathrm{H}_{2} \mathrm{O}_{2}\right)$, the hydroxyl radical $(\cdot \mathrm{OH})$, and the singlet oxygen $\left({ }^{1} \mathrm{O}_{2}\right)$ (Imlay 2003). Indeed, $\mathrm{O}_{2}{ }^{-}$is not very reactive with biomolecules, but it does react rapidly with another molecule of $\mathrm{O}_{2}{ }^{-}$to form $\mathrm{H}_{2} \mathrm{O}_{2}$ or with nitric oxide to form a very potent oxidant and reactive nitrogen species, peroxynitrite (Pacher et al. 2007). $\mathrm{H}_{2} \mathrm{O}_{2}$ is stable, but it is a precursor of free radicals as UV radiation causes the cleavage of the oxygen-oxygen bond to form $\bullet \mathrm{OH}$ through the Fenton reaction in the presence of redox metal ions $\left(\mathrm{Fe}^{2+}\right.$ or $\mathrm{Fe}^{3+}$ or $\left.\mathrm{Cu}^{+}\right)$. The most reactive and least selective 

species is $\bullet \mathrm{OH}$, which reacts with many biomolecules as it diffuses into the cells (Bokare \& Choi 2014). ${ }^{1} \mathrm{O}_{2}$ is a photoexcited form of $\mathrm{O}_{2}$, and is very dangerous as it reacts rapidly with cysteine, histidine, methionine, tyrosine and tryptophan residues, unsaturated lipids and some nucleic acids (Briviba et al. 1997).

Microorganisms routinely generate ROS when they grow in aerobic environments. The accidental autoxidation of flavoenzymes is mainly responsible for $\mathrm{O}_{2}^{-}$and $\mathrm{H}_{2} \mathrm{O}_{2}$ production (Seaver \& Imlay 2004). As microbial life first evolved in a world devoid of $\mathrm{O}_{2}$ and rich in reduced iron, microorganisms evolved strategies to maintain a reducing environment and to prevent damage to essential macromolecules (Anbar 2008). When the balance between ROS and scavenger systems is disturbed, ROS accumulation within the cells leads to a condition called oxidative stress (Cabiscol et al. 2000; Green \& Paget 2004; Imlay 2013). In this condition, the ROS concentration is so high that it can lead to protein, DNA, and lipid damage, an increased rate of mutagenesis, and cell death (Imlay 2013). Bacteria have evolved sensitive and specific sensors to monitor different redox signals such as the presence or absence of $\mathrm{O}_{2}$, cellular redox state or ROS. Thus sensing mechanisms can involve redoxactive cofactors, such as heme, flavins, pyridine nucleotides and iron-sulphur clusters, or redox-sensitive amino acid side chains such as cysteine thiols (Green \& Paget 2004), and are 95 tightly controlled by a complex network of regulators, including OxyR, SoxRS and RpoS.

\section{Environmental sources of ROS} and non-ionizing irradiation (UV) leads to the intracellular formation of ROS because of the ionization of intracellular water (Sies 1997; Matallana-Surget et al. 2009). High temperatures 102 can result in high oxidative stress, leading to damage to proteins, DNA double-strand breaks 

and cell death (Davidson et al. 1996; Murata et al. 2011; Chen et al. 2013). In addition, cold temperatures cause oxidative stress: cells of the Antarctic bacterium Pseudomonas

105 fluorescens, grown at $4^{\circ} \mathrm{C}$, suffer an increasing amount of free radicals and the enhanced 106 activity of two antioxidant enzymes (Chattopadhyay et al. 2011).

107 Another source of oxidative stress, mainly for pathogenic bacteria, is the interaction with the 15 
128 redox in the absence of other electron acceptors (Price-Whelan et al. 2006), and have been

129 proposed as signalling molecules that are involved in quorum sensing (QS) regulated

130 pathways and various stages of biofilm formation (Pierson LS \& Pierson EA 2010).

131 In addition to natural ROS sources, the soil collects environmental pollutants, such as

132 xenobiotics, metals and chemicals, which are able to cause oxidative stress in microorganisms

133 (Kang et al. 2007; Pérez-Pantoja et al. 2013). Titanium oxide and silver nanoparticles are

134 among emerging soil pollutants that cause oxidative stress in soil microorganisms (Polo et al.

135 2011; Mirzajani et al. 2013). Other exogenous sources of ROS are disinfectants and cleaning

136 agents that contain peroxides, chloramines or hypochlorites (Van Houdt \& Michiels 2010),

137 and are increasingly used in a number of medical, food and industrial applications due to their

138 broad spectrum activities and low cost (Linley et al. 2012). Their use has raised concerns

139 about increasing resistance among pathogenic bacteria (Van Houdt \& Michiels 2010) and

140 exposing beneficial soil microbial community to oxidative stress (Ortiz de Orué Lucana et al.

141 2012). Whether antibiotics generate ROS to kill bacteria is an open question. In the last

142 decade, it has been reported that the generation of ROS contributes to the efficacy of

143 aminoglycosides, b-lactams and fluoroquinolones (Kohanski et al. 2007; Foti et al. 2012;

144 Dwyer et al. 2014). However, the difficulty of demonstrating this thesis has highlighted

145 (Ezraty et al. 2013; Keren et al. 2013). This issue has been dealt with in two recent and

146 excellent reviews that summarize the data published so far (Dwyer et al. 2015; Imlay 2015).

\section{Hormetic behaviour of ROS}

148 Hormesis is a dose-response phenomenon characterized by low-dose stimulation and high-

149 dose inhibition; this is represented as an inverted U-shaped dose response (Southam \&

150 Ehrlich 1943; Calabrese et al. 2011). Like many compounds exhibiting hormetic behaviour,

151 ROS can be either detrimental or beneficial, depending on the concentration (Lewis 2008; Pan

53

152 2011). This is because exposure to low levels of the compound, or stress, can induce an 

154 155 156 157 158 159 19 162

adaptive response that protects the organism (Cap et al. 2012). When this occurs, despite lower levels of oxidatively modified biomolecules, it is possible to observe higher antioxidant, or associated enzyme, activity (Lushchak 2014).

The hormetic behavior of ROS in bacteria has important consequences in the sanitary and industrial fields because different doses of antimicrobials can either kill or increase their resistance to antimicrobials (Marathe et al. 2013). There are possible environmental repercussions to water and soil microflora exposed to low (sublethal) concentrations of oxidizing agents (Villa et al. 2012b). Though biocides are generally used at high

161 concentrations to kill bacteria, there are sub-inhibitory biocide levels downstream from the treated area that range from the initial treatment concentration to nil (Gilbert \& Mc Bain 163 2003; Mc Cay et al. 2010). Here, if oxidative stress is very high and so persistent as to exceed 164 the point of no return, it can lead to cell death. However, if there are only moderate levels of 165 stress, protective mechanisms are activated through a complex pathway involving various 166 regulators, so that cell death is avoided (Amitai et al. 2004; Zhao \& Drlica 2014). An example 167 is the Escherichia coli MazE/MazF system, which generates ROS as a stress response. In 168 response to low levels of stress, this system stimulates the activation of protective pathways, 169 including the Cpx envelope protein stress system for the refolding or degradation of 170 misfolded proteins in the periplasm, the inhibition of katG mRNA degradation, and MazF171 mediated $\bullet \mathrm{OH}$ accumulation (Pogliano et al. 1997; Raivio \& Silhavy 2001; Zhao \& Drlica 172 2014). In the case of extreme stress, the same proteins used to trigger ROS scavenging 173 systems contribute to a cascade of ROS, and activate a programmed cell death pathway, 174 essential to reduce the risk of hypermutation and loss of genetic integrity (Dorsey-Oresto et 175 al. 2013). In Bacillus subtilis, NdoA plays the same role as the E. coli MazE/MazF system 176 (Wu et al. 2011). 
177 Bernier \& Surette (2012) has recently stated that different concentrations of antibiotics can

178 trigger different biological responses, varying from cell death (acting as a toxin at a high 179 concentration), adaptation (acting as a stress inducer at a medium concentration), and the shift 180 of metabolic pathways (acting as a cue at a low concentration). Given the hormetic behavior 181 of ROS, the above responses are also true for different levels of oxidative stress. Therefore, 182 the effects of oxidative stress may be even more diverse and less predictable in environmental 183 biofilms than in planktonic cells because of their chemical, physical and biological 184 heterogeneity, and the relationships among biofilm members, each interacting with external 185 chemicals in a particular way.

\section{Biofilm and oxidative stress}

187 The ability to form biofilm is a very ancient and common trait of Archaea and Bacteria, as 188 evidenced by the observation of fossils dating back to 3.25 billion years ago (Hall-Stoodley et 189 al. 2004). At that time, oceans and the atmosphere had a low oxygen content, as the first 190 oxygenation events that changed the redox state of the environment occurred only 2.4 billion 191 years ago (Anbar 2008). Microorganisms altered their metabolism and their defence strategies 192 in order to take advantage of the accumulated oxygen and, at the same time, to avoid the 193 damage caused by oxidative stress (Imlay 2013; Ziegelhoffer \& Donohue 2009). Thus, the 194 microbial biofilm response may have evolved alongside continuous increase of oxygen on 195 Earth to develop a complex regulation of metabolic pathways, sensitive to the concentration, 196 quality and durability of ROS. The authors speculate that the integration of ROS into several 197 different signalling pathways, including the switch between planktonic and sessile forms, 198 could have been, and still is, fundamental, from the eco-evolutionary point of view, to the 199 survival of microbial species. We are suggesting three avenues of research for understanding 200 the link between biofilm and oxidative stress: the existence of common regulators, the 


\section{Common regulators and pathways}

203 The first evidence of the tight connection between oxidative stress and biofilm formation is 10 204 the involvement, in both processes, of the same regulators of many metabolic pathways. 205 Through these pathways, ROS deeply influence bacterial physiology in biofilm (Cap et al. 206 2012), affecting its characteristics, structure and morphology (see examples in Villa et al. 207 2012b; DePas et al. 2013; Milferstedt et al. 2013 and in Figure 2). This may be understood as the result of the coevolution of biofilm and oxygen on Earth, which may have integrated ROS as a versatile and dynamic signal in many cellular pathways, including mechanisms regulating 210 biofilm formation. In biofilm, cells are able not only to face oxidative stress, but also to 211 exploit it, using ROS as a signal or cue to prepare to adapt to a changing environment. It is 212 tempting to speculate that ROS signalling may be a driving force for the dominance of 213 biofilm in many environmental niches. For instance, genome sequence analyses of deep-sea 214 sedimentary bacterium Pseudoalteromonas sp. SM9913 which live at a very low oxygen 215 concentration, compared to that of the closely related Antarctic surface sea-water ecotype 216 Pseudoalteromonas haloplanktis TAC125, revealed a higher sensitivity to ROS, but also a 217 potentially increased ability to form biofilm once exposed to oxygen (Qin et al., 2011). 
chlororaphis (Xie et al. 2013) and Porphyromonas gingivalis (Wu et al. 2008) show increased

228 10

ability to form biofilm in minimal medium and higher sensitivity to $\mathrm{H}_{2} \mathrm{O}_{2}$ and paraquat (a

229 redox cycling agent, ie a compound able to produce ROS by changing its oxidative state). In

230 P. aeruginosa biofilm exposed to oxidative stress, OxyR promotes the biofilm lifestyle to

231 reduce metabolism and ROS production but also to encourage the dispersion of stressed

232 bacteria (Wei et al. 2012). Indeed in P. aeruginosa, the oxidized form of OxyR binds both the

233 promoter region of the bacteriophage Pf4 operon, essential for biofilm formation (Rice et al.

234 2009), and of $b d l A$, a biofilm dispersion locus (Morgan et al. 2006). However, the opposite

235 effect has been described in Serratia marcescens, Neisseria gonorrhoeae and Tannerella

236 forsythia, whose oxyR mutant strains show an impaired ability to form biofilm (Seib et al.

237 2007; Shanks et al. 2007; Honma et al. 2009).

238 RpoS is a general stress response protein that up-regulates cellular stress-related genes in 239 response to slow growth, both in the stationary phase and under stress conditions (Hengge240 Aronis 1999). In E. coli, RpoS is also activated in response to oxidative stress, collaborating 241 to scavenge ROS with OxyR and SoxRS and inducing the transcription of genes involved in 242 the protection from oxidative damage (ie $d s p A$, katE and $\operatorname{sod} C$ ) (Schellhorn \& Stones 1992; 243 Patten et al. 2004). Moreover, RpoS plays an essential role during biofilm development 244 because it controls the expression of almost $50 \%$ of the genes that specifically induce the 245 growth of biofilm (Collet et al. 2008). Recent studies highlight a more complex picture adding 246 that RpoS triggers the production of extracellular structures and biofilm formation only under 247 conditions of limited nutrient availability (Corona-Izquierdo \& Membrillo-Hernandez 2002;

248 Sheldon et al. 2012). For instance, in Klebsiella pneumonia, RpoS and SoxR trigger the 249 expression of $\mathrm{YjcC}$, a protein that regulates both the oxidative stress response and biofilm 250 production by modulating the levels of the second messenger cyclic di-GMP (c-di-GMP) 251 (Huang et al. 2013). In the food borne pathogen Campylobacter jejuni, it is not OxyR and 
SoxRS that regulate the genes of oxidative stress resistance, it is PerR, Fur and CosR (Atack

\& Kelly 2009). Under their control, AhpC, the only alkyl hydroperoxide reductase in this

254 bacterium, negatively affects biofilm formation, maybe decreasing the oxidative stress levels 255 in cell aggregates (Oh \& Jeon 2014).

256 Quorum-sensing (QS) is a mechanism that enables bacteria to make collective decisions, 257 synchronize with the rest of the population and thus function as multicellular organisms 258 (Waters \& Bassler 2005). In P. aeruginosa, QS-deficient mutants (lasI, rhlI and lasI rhlI) are 259 more likely to suffer from oxidative stress because of the lower expression of katA and sodA 260 (Hassett et al. 1999). In P. aeruginosa, QS enhances the oxidative stress response, triggering 261 the production of scavenging enzymes; cells with an active QS system are more resistant to 262 oxidative damage and will be selected by oxidative stress (García-Contreras et al. 2015). In $B$. 263 pseudomallei, DpsA binds DNA and sequesters iron (Martinez \& Kolter 1997) to protect 264 DNA from damage by both acid and oxidative stress (Loprasert et al. 2004). At the same 265 time, bpsRI mutants, unable to produce the QS molecules N-octanoylhomoserine lactone and $266 \mathrm{~N}$-(3-oxooctanoyl) homoserine lactone, show a reduced $d p s A$ expression, and thus a higher 267 sensitivity to organic hydroperoxides (Lumjiaktase et al. 2006). Lumjiaktase et al. (2006) also 268 hypothesized that the control of the oxidative stress response through QS could be useful in 269 high-density cultures, eg biofilm or stationary phase cultures, to protect DNA from oxidative 270 damage. More recently, proteomic analysis of $B$. subtilis biofilm exposed to sublethal doses of 271 silver nanoparticles, producing ROS, revealed a higher expression of proteins involved in 272 stress responses (including oxidative stress proteins AhpC, SufD and thioredoxin) and 273 quorum sensing (DegU, OppF, CotE and SrfAB), thus affecting gene expression in B. subtilis 274 biofilms (Gambino et al. 2015).

275 The production of phenazines is another pathway that connects biofilm and oxidative stress. 276 Phenazines are a large group of nitrogen-containing heterocyclic compounds with different 
277 chemical and physical properties depending on the functional groups present (Mavrodi et al. 278 2010). Mainly studied in pseudomonads, they work as an electron shuttle and are essential for 279 long term survival under anaerobic conditions, eg in the inner part of biofilms, and they 280 generate ROS in other organisms such as Candida albicans (Drago 2009). Phenazines are

282 Pierson LS \& Pierson EA 2010). It has been observed in P. chloraphis that mutant strains 283 deficient in phenazine are not able to form biofilm (Maddula et al. 2006). Moreover, $P$. chlororaphis produces different ratios of various phenazine derivatives, depending on the needs of the population, as each derivative has particular characteristics. For example, it has been supposed that 2-hydroxy-phenazine-1-carboxylic acid could facilitate cellular adhesion, whereas phenazine-1-carboxylic acid might allow biofilm growth, by acting as an electron shuttle within the microaerophilic community (Pierson LS \& Pierson EA 2010). Phenazine production is also one of the most efficient strategies to acquire iron from the environment, a condition that significantly influences the switch from a planktonic to a sessile lifestyle in $P$. aeruginosa (Cornelis \& Dingemans 2013).

Other pathways connecting oxidative stress and biofilm will surely come to the fore in the next few years. For example, Marinomonas mediterranea, a component of the microbiota associated with the marine plant Posidonia oceanica, expresses an antimicrobial protein with lysine oxidase activity (Molina-Quintero et al. 2010). This protein generates hydrogen peroxide that facilitates the subsequent dispersal of cells from biofilm, but the regulation mechanisms are not yet completely understood (Lucas-Elio et al. 2012).

The presence of common regulators and pathways between biofilm and oxidative stress could be exploited; as a novel biocide-free strategy; for biofilm control. Villa et al. (2012c) found that $E$. coli cells exposed to sublethal concentrations of zosteric acid, a natural compound from Zostera marina, accumulate ROS, activate scavenging mechanisms and induce a 

hypermotile phenotype, which inhibits the formation of biofilm. More recently, it has been hypothesized that this anti-biofilm compound could increase ROS accumulation by inhibiting the oxidoreductase activity of WrbA, a NADH:quinone reductase, interfering with the QS system and biofilm formation (Cattò et al. 2015). Therefore, zosteric acid seems to act as an environmental cue, warning microorganisms about environmental changes and to prepare for 307 adversity (Villa et al. 2012c).

\section{Extracellular polymeric substances (EPS) production}

309 The EPS production pathway is inevitably connected to environmental stress sensors and is

310 activated in accordance with external conditions.

Formatted: English (U.K.)

311 Among EPS, extracellular polysaccharides are often involved in the oxidative stress response.

For example, increased production of polysaccharides was observed in the Azotobacter

vinelandii (Villa et al. 2012b) (Figure 3) and B. subtilis biofilm matrices (Gambino et al. 2015), when exposed to sources of oxidative stress. Alginate, an extracellular polysaccharide 315 produced by pseudomonads and A. vinelandii, among others, is able to scavenge hydroxyl 316 radicals $(\cdot \mathrm{OH})$, in order to inhibit lipid and protein peroxidation (Tomida et al. 2010). Alginate is also used by $P$. aeruginosa to scavenge the $\mathrm{H}_{2} \underline{\mathrm{O}}_{2}$ released to kill pathogens by macrophages, neutrophils and the hypersensitive response-plant-defence system (Mathee et 319 al. 1999; Hay et al. 2014). The network regulating alginate production is controlled through 320 the cross-talk of different regulators, but it the mechanisms behind the specific environmental 321 cues that induce alginate production are unclear (Hay et al. 2014). Another example is the 322 production of colanic acid by E. coli biofilm, promoted by the GGDEF protein YddV, under 323 the regulation of $r p o S$. In addition to promoting cell aggregation and colanic acid production 
However, EPS may be produced as a response to exogenous oxidative stress not to scavenge ROS directly but as part of the cells effort to decrease their metabolism to limit its own ROS production. This is the case of the B. pseudomallei succinyl-coA:3-ketoacid-coenzyme A transferase enzyme, which is down-regulated upon oxidative stress to avoid ROS production and leads to the accumulation of poly-hydroxybutyrate within cells as storage molecules

\section{1 (Chutoam et al. 2013).}

332 EPS is a physical and chemical barrier for biocidal compounds and the attack of predators 333 (Costerton \& Lewandoski 1995), both of which produce ROS (see 'Environmental sources of 334 ROS' section). Although reducing diffusion through the biofilm matrix only provides a short335 term protective effect against many ROS producing compounds (Walters et al. 2003), it could 336 be enough for sessile cells to rapidly adapt and scavenge different forms of ROS, enabling 337 dynamic changes in ROS levels.

\section{Biofilm heterogeneity}

339 Biofilm represents a very heterogeneous environment both spatially and temporally, enclosing 340 many microenvironments with different characteristics in a continuous flux of chemical 341 gradients, which are influenced by the metabolism of resident bacteria, transport limitations 342 (Teal et al. 2006) and the aging of the biofilm (Saint-Ruf et al. 2014). Every single cell 343 forming a biofilm responds to environmental changes in an individual and unique way 344 (Monds \& O'Toole 2009). In every microenvironment within the biofilm, the local conditions 345 trigger a differential response in bacteria, and select for more favorable phenotype variants. 346 Thus, phenotype variants arise from both stochastic gene expression and genetic variation 347 (mutation and genetic rearrangements) (Stewart \& Franklin 2008). Oxidative stress is one of 348 the main sources of heterogeneity in many bacterial biofilms (Saint-Ruf et al. 2014). In 349 biofilm, each individual cell is exposed differentially to the surrounding environment, senses 
ROS at different levels, and activates its own ROS scavenging mechanisms, creating gradients of different ROS forms and increasing the variance of phenotypes.

In E. coli, exposure to iron causes ROS accumulation; and triggers the development of rugose 
375 enhance heterogeneity and matrix production in biofilm, increasing the number of persistent

376 cells (Wu et al. 2012) and playing an important role in the higher tolerance of biofilm to

377 antimicrobials. Furthermore, the resistance to antimicrobials that can arise in a biofilm is not 378 necessarily contained to the biofilm. Any change in environmental conditions can lead to the 379 dispersion of biofilm cells that colonize new niches with the antibiotic resistance they have

380 already acquired.

\section{Conclusion}

382 The role of oxidative stress in bacterial biofilms is a topic of outstanding importance because 383 it is relevant to the sanitary, industrial and environmental fields. The development of 384 antimicrobial resistance in biofilms demand attention because ROS may trigger adaptive 385 mechanisms that are more effective in biofilms than in planktonic bacteria. In this review, 386 three avenues of research have been highlighted for further investigations into the biofilm 387 response to oxidative stress, but others may arise with further research in the field. 388 Unravelling the different interactions that tie biofilm response to oxidative stress will be a 389 challenge for many years to come. Understanding the mechanisms regulating biofilm in 390 response to different levels of ROS may shed light on both the environmental determinants 391 for the bacterial colonization of hostile habitats and the molecular strategies used to sense 392 environmental cues and adapt accordingly. An explanation of these pathways could be the key 393 to identify which mechanisms lead to the colonization of habitats of ecological and economic 394 interest. In the near future, it may also be possible to use oxidative stress in a controlled way 395 to trigger biofilm formation and dispersal.

\section{Disclosure}

398 The authors report no conflicts of interest in this work. 
399 References

400 Amitai S, Yassin Y, Engelberg-Kulka H. 2004. MazF-mediated cell death in Escherichia coli:

401 a point of no return. J Bacteriol 186:8295-8300.

402 Anbar AD. 2008. Elements and evolution. Science 322:1481-1483.

403 Apel K, Hirt H. 2004. Reactive oxygen species: metabolism, oxidative stress, and signal 404 transduction. Annu Rev Plant Biol 55:373-399.

405 Arce Miranda JE, Sotomayor CE, Albesa I, Paraje MG. 2011. Oxidative and nitrosative stress 406 in Staphylococcus aureus biofilm. FEMS Microbiol Lett 315:23-29.

407 Atack JM, Kelly DJ. 2009. Oxidative stress in Campylobacter jejuni: responses, resistance 408 and regulation. Future Microbiol 4:677-690.

409 Bai AJ, Rai VR. 2011. Bacterial quorum sensing and food industry. Compr Rev Food Sci 410 Food Saf 10:184-194.

411 Bernier SP, Surette MG. 2013. Concentration-dependent activity of antibiotics in natural 412 environments. Front Microbiol 4:1-14.

413 Bjarnsholt T, Alhede M, Alhede M, Eickhardt-Sørensen SR, Moser C, Kuhl M, Jensen PO, 414 Høiby N. 2013. The in vivo biofilm. Trends Microbiol. 21:466-474.

415 Bokare AD, Choi W. 2014. Review of iron-free Fenton-like systems for activating $\mathrm{H}_{2} \mathrm{O}_{2}$ in 416 advanced oxidation processes. J Hazard Mat 275:121-135.

417 Boles BR, Singh PK. 2008. Endogenous oxidative stress produces diversity and adaptability 418 in biofilm communities. Proc Natl Acad Sci U S A 105:12503-12508.

419 Briviba K, Klotz LO, Sies H. 1997. Toxic and signaling effects of photochemically or 420 chemically generated singletoxygenin biological systems. Biol Chem 378:1259-1265.

421 Bruellhoff K, Fiedler J, Möller M, Groll J, Brenner RE. 2010. Surface coating strategies to 422 prevent biofilm formation on implant surfaces. Int J Artif Organs 33:646-653. 
423 Cabiscol E, Tamarit J, Ros J. 2000. Oxidative stress in bacteria and protein damage by 424 reactive oxygen species. Intern Microbiol 3:3-8.

425 Calabrese V, Cornelius C, Cuzzocrea S, Iavicoli I, Rizzarelli E, Calabrese EJ. 2011. 426 Hormesis, cellular stress response and vitagenes as critical determinants in aging and 427 longevity. Molec Aspects Med 32:279-304.

428 Cáp M, Váchová L, Palková Z. 2012. Reactive oxygen species in the signaling and adaptation 429 of multicellular microbial communities. Oxid Med Cell Longev 976753.

430 Cappitelli F, Principi P, Sorlini C. 2006. Biodeterioration of modern materials in 431 contemporary collections: can biotechnology help? Trends Biotechnol 24:350-354.

432 Cappitelli F, Polo A, Villa F. 2014. Biofilm formation in food processing environments is still 433 poorly understood and controlled. Food Engineer Rev 6: 29-42.

434 Cattò C, Dell'Orto S, Villa F, Villa S, Gelain A, Vitali A, Marzano V, Baroni S, Forlani F, 435 Cappitelli F. 2015. Unravelling the structural and molecular basis responsible for the anti436 biofilm activity of zosteric acid. PloS One 10:e0131519.

437 Cegelski L, Marshall GR, Eldridge GR, Hultgren SJ. 2008. The biology and future prospects 438 of antivirulence therapies. Nat Rev Microbiol 6:17-27.

439 Chattopadhyay MK, Raghu G, Sharma YV, Biju AR, Rajasekharan MV, ShivajiS. 2011. 440 Increase in oxidative stress at low temperature in an antarctic bacterium. Curr Microbiol $441 \quad 62: 544-546$.

442 Chen J, Shen J, Solem C, Jensen PR. 2013. Oxidative stress at high temperatures in 443 Lactococcus lactis due to an insufficient supply of riboflavin. Appl Environ Microbiol $444 \quad 79: 6140-6147$.

445 Chutoam $\mathrm{P}$, Charoensawan V, Wongtrakoongate $\mathrm{P}$, Kumarth A, Buphamalai $\mathrm{P}$, 446 Tungpradabkul S. 2013. RpoS and oxidative stress conditions regulate succinyl-CoA: 3- 
447 ketoacid-coenzyme A transferase (SCOT) expression in Burkholderia pseudomallei.

448 Microbiol Immunol 57:605-615.

449 Clare AS, Rittschof D, Gerhart D, Maki J. 1992. Molecular approaches to nontoxic 450 antifouling. Invertebr Reprod Dev 22:67-76. 452229.

453 Collet A, Cosette P, Beloin C, Ghigo JM, Rihouey C, Lerouge P, Junter GA, Jouenne T. 2008 454 Impact of rpoS deletion on the proteome of Escherichia coli grown planktonically and as 455 biofilm. J Proteome Res 7:4659-4669.

456 Cornelis P, Dingemans J. 2013. Pseudomonas aeruginosa adapts its iron uptake strategies in 457 function of the type of infections. Front Cell Infect Microbiol 3:1-7.

458 Corona-Izquierdo FP, Membrillo-Hernández J. 2002. A mutation in rpoS enhances biofilm 459 formation in Escherichia coli during exponential phase of growth. FEMS Microbiol Lett $460 \quad 211: 105-110$.

461 Conlin PL, Chandler JR, Kerr B. 2014. Games of life and death: antibiotic resistance and 462 production through the lens of evolutionary game theory. Curr Opin Microbiol 21:35-44.

463 Costerton JW, Cheng KJ, Geesy GG, Ladd TI, Nickel JC, Dasgupta M, Marrie TJ. 1987. 464 Bacterial biofilms in nature and disease. Annu Rev Microbiol 41:435-464.

465 Danese PN, Pratt L, Dove SL, Kolter R. 2000. The outer membrane protein, Antigen 43, 466 mediates cell-to-cell interactions within Escherichia coli biofilms. Mol Microbiol 37:424467432.

468 Dash HR, Mangwani N, Chakraborty J, Kumari S, Das S. 2013. Marine bacteria: potential 469 candidates for enhanced bioremediation. Appl Microb Biotechnol 97:561-571.

470 Davey ME, O’Toole G. 2000. Microbial biofilms: from ecology to molecular genetics. 471 Microbiol Mol Biol Rev 64:847-867. 
472 Davidson JF, Whyte B, Bissinger PH, Schiestl RH. 1996. Oxidative stress is involved in heat473 induced cell death in Saccharomyces cerevisiae. Proc Natl Acad Sci U S A 93:5116-5121.

474 DePas WH, Hufnagel D, Lee JS, Blanco LP, Bernstein HC, Fisher ST, James GA, Stewart 475 PS, Chapman, MR. 2013. Iron induces bimodal population development by Escherichia coli. 476 Proc Natl Acad Sci U S A. 110:2629-2634.

477 Dietrich LEP, Teal TK, Price-Whelan A, Newman DK. 2008. Redox-active antibiotics control 478 gene expression and community behavior in divergent bacteria. Science 321:1203-1206.

479 Dorsey-Oresto A, Lu T, Mosel M, Wang X, Salz T, Drlica K, Zhao X. 2013. YihE Kinase is a 480 central regulator of programmed cell death in bacteria. Cell Reports 3:528-537.

481 Drago L. 2009 Bacteria and biofilm in respiratory tract infections. Infect Med 17:3-9.

482 Dwyer DJ, Belenky PA, Yang JH, MacDonald IC, Martell JD, Takahashi N, Chan CT, 483 Lobritz MA, Braff D, Schwarz EG, Ye JD, Pati M, Vercruysse M, Ralifo PS, Allison KR, 484 Khalil AS, Ting AY, Walker GC, Collins JJ. 2014. Antibiotics induce redox-related 485 physiological alterations as part of their lethality. Proc Natl Acad Sci USA 111:E2100-2109.

486 Dwyer DJ, Collins JJ, Walker GC. 2015. Unraveling the physiological complexities of 487 antibiotic lethality. Annu Rev Pharmacol Toxicol 55:313-332.

488 Ezraty B, Vergnes A, Banzhaf M, Duverger Y, Huguenot A, Brochado AR, Su SY, Espinosa 489 L, Loiseau L, Py B, Barras F. 2013. Fe-S cluster biosynthesis controls uptake of 490 aminoglycosides in a ROS-less death pathway. Science 340:1583-1587.

491 Fester T, Hause G. 2005. Accumulation of reactive oxygen species in arbuscular mycorrhizal 492 roots. Mycorrhiza 15:373-379.

493 Flemming HC, Neu TR, Wozniak DJ. 2007. The EPS matrix: the "house of biofilm cells". J 494 Bacteriol 189:7945-7947.

495 Flemming H, Wingender J. 2010. The biofilm matrix. Nat Rev Microbiol 8:623-633. 
Foti JJ, Devadoss B, Winkler JA, Collins JJ, Walker GC. 2012. Oxidation of the guanine nucleotide pool underlies cell death by bactericidal antibiotics. Science 336:315-319.

Gambino M, Marzano V, Villa F, Vitali A, Vannini C, Landini P, Cappitelli F. 2015. Effects of sub-lethal doses of silver nanoparticles on Bacillus subtilis planktonic and sessile cells. J Appl Microbiol 118:1103-1115.

501 García-Contreras R, Nuñez-López L, Jasso-Chávez R, Kwan BW, Belmont J, Rangel-Vega 502 A, Belmont JA, Rangel-Vega A, Maeda T, Wood TK. 2015. Quorum sensing enhancement of 503 the stress response promotes resistance to quorum quenching and prevents social cheating. 504 ISME J 9:115-125.

505 Garin J, Diez R, Kieffer S, Dermine JF, Duclos S, Gagnon E, Sadoul R, Rondeau C, 506 Desjardins M. 2001. The phagosome proteome: insight into phagosome functions. J Cell Biol $507 \quad 152: 165-180$.

508 Gerschman R, Gilbert DL, Nye SW, Dwyer P, Fenn WO. 1954. Oxygen poisoning and X509 irradiation: a mechanism in common. Science 119:623-626.

510 Gilbert P, Mc Bain AJ. 2003. Potential impact of increased use of biocides in consumer 511 products on prevalence of antibiotic resistance. Clin Microbiol Rev 16:189-208.

512 Green J, Paget MS. 2004. Bacterial redox sensors. Nat Rev Microbiol 2:954-966.

513 Guerrero R, Margulis L, Berlanga M. 2013. Symbiogenesis: the holobiont as a unit of 514 evolution. Int Microbiol 16:133-143.

515 Hadfield MG. 2011. Biofilms and marine invertebrate larvae: what bacteria produce that 516 larvae use to choose settlement sites. Ann Rev Mar Sci 3:453-479.

517 Hall-Stoodley L, Costerton JW, Stoodley P. 2004. Bacterial biofilms: from the natural 518 environment to infectious diseases. Nat Rev Microbiol 2:95-108.

519 Hassett DJ, Ma JS, Elkins JG, McDermott T, Ochsner UA, West SE, Huang CT, Fredericks J, 520 Burnett S, Stewart PS, McFeters G, Passador L, Iglewski BH. 1999. Quorum sensing in 
521 Pseudomonas aeruginosa controls expression of catalase and superoxide dismutase genes and 522 mediates biofilm susceptibility to hydrogen peroxide. Mol Microbiol 34:1082-1093.

523 Hay ID, Wang Y, Moradali MF, Rehman ZU, Rehm BH. 2014. Genetics and regulation of 524 bacterial alginate production. Environ Microbiol 16:2997-3011.

525 Hengge-Aronis R. 1999. Interplay of global regulators and cell physiology in the general 526 stress response of Escherichia coli. Curr Opin Microbiol 2:148-152.

527 Honma K, Mishima E, Inagaki S, Sharma A. 2009. The OxyR homologue in Tannerella 528 forsythia regulates expression of oxidative stress responses and biofilm formation. 529 Microbiology 155:1912-1922.

530 Huang CJ, Wang ZC, Huang HY, Huang HD, Peng HL. 2013. YjcC, a c-di-GMP 531 phosphodiesterase protein, regulates the oxidative stress response and virulence of Klebsiella 532 pneumoniae CG43. PloS One 8:e66740.

533 Imlay J. 2003. Pathways of oxidative damage. Annu Rev Microbiol 57:395-418.

534 Imlay J. 2013. The molecular mechanisms and physiological consequences of oxidative 535 stress: lessons from a model bacterium. Nat Rev Microbiol 11:443-54.

536 Imlay J. 2015. Diagnosing oxidative stress in bacteria: not as easy as you might think. Curr 537 Opin Microbiol 24:124-131.

538 Jamet A, Siguad S, Van de Sype G, Puppo A, Herouart D. 2003. Expression of the bacterial 539 catalase genes during Sinorhizobium meliloti- Medicago sativa symbiosis and their crucial 540 role during the infection process. Mol Plant Microbe Interact 16:217-225.

541 Jasso-Chávez R, Santiago-Martínez MG, Lira-Silva E, Pineda E, Zepeda-Rodríguez A, 542 Belmont-Díaz J, Encalada R, Saavedra E, Moreno-Sánchez R. 2015. Air-adapted 543 Methanosarcina acetivorans shows high methane production and develops resistance against 544 oxygen stress. Plos One 10:1-21. 
545 Kang YS, Lee Y, Jung H, Jeon CO, Madsen EL, Park W. 2007. Overexpressing antioxidant 546 enzymes enhances naphthalene biodegradation in Pseudomonas sp. strain As1. Microbiology $547 \quad 153: 3246-3254$.

548 Keren I, Wu Y, Inocencio J, Mulcahy LR, Lewis K. 2013. Killing by bactericidal antibiotics 549 does not depend on reactive oxygen species. Science 339:1213-1216.

550 Kohanski MA, Dwyer DJ, Hayete B, Lawrence CA, Collins JJ. 2007. A common mechanism 551 of cellular death induced by bactericidal antibiotics. Cell 130:797-810.Landini P. 2009. 552 Cross-talk mechanisms in biofilm formation and responses to environmental and 553 physiological stress in Escherichia coli. Res Microbiol 160:259-266.

554 Landini P, Antoniani D, Burgess JG, Nijland R. 2010. Molecular mechanisms of compounds 555 affecting bacterial biofilm formation and dispersal. Appl Microbiol Biotechnol 86:813556 823.Lewis K. 2008. Multidrug tolerance of biofilms and persister cells. Curr Topics Microbiol 557 Immunol 322:107-131.

558 Ligeza A, Tikhonov AN, Hyde JS, Subczynski WK. 1998. Oxygen permeability of thylakoid 559 membranes: electron paramagnetic resonance spin labeling study. Biochim Biophys Acta $560 \quad 1365: 453-463$.

561 Linley E, Denyer SP, McDonnell G, Simons C, Maillard JY. 2012. Use of hydrogen peroxide 562 as a biocide: new consideration of its mechanisms of biocidal action. J Antimicrob Chemother $563 \quad 67: 1589-1596$.

564 Loprasert S, Sallabhan R, Whangsuk W, Mongkolsuk S. 2000. Characterization and 565 mutagenesis of fur gene from Burkholderia pseudomallei. Gene 254:129-137.

566 Loprasert S, Whangsuk W, Sallabhan R, Mongkolsuk S. 2004. DpsA protects the human 48 568101. 
569 Lucas-Elío P, Goodwin L, Woyke T, Pitluck S, Nolan M, Kyrpides NC, Detter JC, Copeland 570 A, Teshima H, Bruce D, Detter C, Tapia R, Han S, Land ML, Ivanova N, Mikhailova N, 571 Johnston A, Sanchez-Amat A. 2012. Complete genome sequence of the melanogenic marine 572 bacterium Marinomonas mediterranea type strain (MMB-1(T)). Stand Genomic Sci 6:63-73. 573 Lumjiaktase P, Diggle SP, Loprasert S, Tungpradabkul S, Daykin M, Cámara M, Williams P, 574 Kunakorn M. 2006. Quorum sensing regulates $d p s A$ and the oxidative stress response in 575 Burkholderia pseudomallei. Microbiology 152:3651-3659.

576 Lushchak VI. 2014. Free radicals, reactive oxygen species, oxidative stress and its 577 classification. Chem Biol Interact. 224:164-175.

578 Maddula VS, Zhang Z, Pierson EA, Pierson LS. 2006. Quorum sensing and phenazines are 579 involved in biofilm formation by Pseudomonas chlororaphis (aureofaciens) strain 30-84. 580 Microb Ecol 52:289-301.

581 Mah TF, Pitts B, Pellock B, Walker GC, Stewart PS. 2003. A genetic basis for Pseudomonas 582 aeruginosa biofilm antibiotic resistance. Nature 426:306-310.

583 Marathe SA, Kumar R, Ajitkumar P, Nagaraja V, Chakravortty D. 2013 Curcumin reduces 584 the antimicrobial activity of ciprofloxacin against Salmonella typhimurium and Salmonella 585 typhi. J Antimicrob Chemother 68:139-152.

586 Martinez A, Kolter R. 1997. Protection of DNA during oxidative stress by the nonspecific 587 DNA-binding protein Dps. J Bacteriol 179:5188-5194.

588 Martinez JL. 2009. The role of natural environments in the evolution of resistance traits in 589 pathogenic bacteria. Proc Biol Sci 276:2521-2530.

590 Matallana-Surget S, Joux F, Raftery MJ, Cavicchioli R. 2009. The response of the marine 591 bacterium Sphingopyxis alaskensis to solar radiation assessed by quantitative proteomics. 592 Environ Microbiol 11:2660-2675. 
593 Mathee K, Ciofu O, Sternberg C, Lindum PW, Campbell JI. 1999. Mucoid conversion of 594 Pseudomonas aeruginosa by hydrogen peroxide: a mechanism for virulence activation in the 595 cystic fibrosis lung. Microbiology 145:1349-1357.

596 Mavrodi DV, Peever TL, Mavrodi OV, Parejko J, Raaijmakers JM, Lemanceau P, Mazurier 597 S, Heide L, Blankenfeldt W, Weller DW, Thomashow LS. 2010. Diversity and evolution of 598 the phenazine biosynthesis pathway. Appl Environ Microbiol 76:866-879.

599 Mc Cay PH, Ocampo-Sosa AA, Fleming GT. 2010. Effect of subinhibitory concentrations of 600 benzalkonium chloride on the competitiveness of Pseudomonas aeruginosa grown in 601 continuous culture. Microbiology 156:30-38.

602 Mc Dougald D, Rice S, Barraud N, Steinberg PD, Kjelleberg S. 2011. Should we stay or 603 should we go: mechanisms and ecological consequences for biofilm dispersal. Nat Rev 604 Microbiol 10:39-50.

605 Méndez-Ortiz MM, Hyodo M, Hayakawa Y, Membrillo-Hernández J. 2006. Genome-wide 606 transcriptional profile of Escherichia coli in response to high levels of the second messenger 607 3',5'-cyclic diguanylic acid. J Biol Chem 281:8090-8099.

608 Milferstedt K, Santa-Catalina G, Godon JJ, Escudié R, Bernet N. 2013. Disturbance 609 frequency determines morphology and community development in multi-species biofilm at 610 the landscape scale. PLoS One 8: 1-14.

611 Mirzajani F, Askari H, Hamzelou S, Farzaneh M, Ghassempour A. 2013. Effect of silver 612 nanoparticles on Oryza sativa L. and its rhizosphere bacteria. Ecotoxicol Environ Saf 88:4861354.

614 Molina-Quintero LR, Lucas-Elío P, Sanchez-Amat A. 2010. Regulation of the Marinomonas 615 merditerranea antimicrobial protein lysine oxidase by L-lysine and the sensor histidine kinase 616 PpoS. Appl Environ Microbiol 76:6141-6149. 
617 Monds RD, O'Toole G. 2009. The developmental model of microbial biofilms: ten years of a 618 paradigm up for review. Trends Microbiol 17: 73-87.

619 Morgan R, Kohn S, Hwang SH, Hassett DJ, Sauer K. 2006. BdlA, a chemotaxis regulator 620 essential for biofilm dispersion in Pseudomonas aeruginosa. J Bacteriol 188:7335-7343.

621 Murata M, Fujimoto H, Nishimura K, Charoensuk K, Nagamitsu H, Raina S, Kosaka T, 622 Oshima T, Ogasawara N, Yamada M. 2011. Molecular strategy for survival at a critical high 623 temperature in Escherichia coli. PLoS One 6:e0020063.

624 Nanda AK, Andrio E, Marino D, Pauly N, Dunand C. 2010. Reactive oxygen species during 625 plant-microorganism early interactions. J Integrative Plant Biol 52:195-204.

626 Nicolella C. 2000. Wastewater treatment with particulate biofilm reactors. J Biotechnol 80:162733

628 Oh E, Jeon B. 2014. Role of alkyl hydroperoxide reductase (AhpC) in the biofilm formation 629 of Campylobacter jejuni. PLoS One 9:e87312.

630 Ortiz de Orué Lucana D, Wedderhoff I, Groves MR. 2012. ROS-mediated signalling in 631 bacteria: zinc-containing Cys-X-X-Cys redox centres and iron-based oxidative stress. J Signal 632 Transd 2012:1-9.

633 Pacher P, Beckman JS, Liaudet L. 2007. Nitric oxide and peroxynitrite in health and disease. 634 Physiol Rev 87:315-424.

635 Painter KL, Strange E, Parkhill J, Bamford KB, Armstrong-James D, Edwards AM. 2015. 636 Staphylococcus aureus adapts to oxidative stress by producing $\mathrm{H}_{2} \mathrm{O}_{2}$-resistant small colony 637 variants via the SOS response. Infection Immun 83:1830-1844.

638 Pan Y. 2011. Mitochondria, reactive oxygen species, and chronological aging: a message 639 from yeast. Experim Gerontol 46:847-852. 
643 Pérez-Pantoja D, Nikel PI, Chavarría M, de Lorenzo V. 2013. Endogenous stress caused by 644 faulty oxidation reactions fosters evolution of 2, 4-dinitrotoluene-degrading bacteria. PLoS 645 Genetics 9:e1003764.

646 Peulen TO, Wilkinson KJ. 2011. Diffusion of nanoparticles in a biofilm. Environ Sci Technol $647 \quad 45: 3367-3373$.

648 Pierson LS, Pierson EA. 2010. Metabolism and function of phenazines in bacteria: impacts on 649 the behavior of bacteria in the environment and biotechnological processes. Appl Microbiol 650 Biotechnol 86:1659-1670.

651 Pogliano J, Lynch AS, Belin D, Lin EC, Beckwith J. 1997. Regulation of Escherichia coli cell 652 envelope proteins involved in protein folding and degradation by the Cpx two-component 653 system. Genes Dev. 11:1169-1182.

654 Polo A, Diamanti MV, Bjarnsholt T, Høiby N, Villa F, Pedeferri MP, Cappitelli F. 2011. 655 Effects of photoactivated titanium dioxide nanopowders and coating on planktonic and 656 biofilm growth of Pseudomonas aeruginosa. Photochem Photobiol 87:1387-1394.

657 Polo A, Foladori P, Ponti B, Bettinetti R, Gambino M, Villa F, Cappitelli F. 2014. Evaluation 658 of zosteric acid for mitigating biofilm formation of Pseudomonas putida isolated from a 659 membrane bioreactor system. Int J Mol Sci 15:9497-9518.

660 Price-Whelan A, Dietrich LE, Newman DK. 2006. Rethinking 'secondary' metabolism: 661 physiological roles for phenazine antibiotics. Nat Chem Biol 2:71-78.

662 Qin Q-L, Li Y, Zhang Y-J, Zhou Z-M, Zhang W-X, Chen X-L, Zhang X-Y, Zhou B-C, Wang 663 L, Zhang Y-Z. 2011. Comparative genomics reveals a deep-sea sediment-adapted life style of 664 Pseudoalteromonas sp. SM9913. ISME J 5:274-84. 
665 Raivio TL, Silhavy TJ. 2001. Periplasmic stress and ECF sigma factors. Annu Rev Microbiol $66655: 591-624$

667 Rice S, Tan CH, Mikkelsen PJ, Kung V, Tay M, Hauser A, McDougald D, Webb JS, 668 Kjelleberg S. 2009. The biofilm life-cycle and virulence of Pseudomonas aeruginosa are 669 dependent on a filamentous prophage. ISME J 3:271-282.

670 Rinaudi LV, Giordano W. 2010. An integrated view of biofilm formation in rhizobia. FEMS 671 Microbiol Lett 304:1-11.

672 Rosenberg E, Koren O, Reshef L, Efrony R, Zilber-Rosenberg I. 2007. The role of 673 microorganisms in coral health, disease and evolution. Nat Rev Microbiol. 5:355-362.

674 Rubio MC, James EK, Clemente MR, Bucciarelli B, Fedorova M, Vance CP, Becana M. 675 2004. Localization of superoxide dismutases and hydrogen peroxide in legume root nodules. 676 Mol Plant Microbe Interact 17:1294-1305.

677 Rudrappa T, Biedrzycki ML, Bais HP. 2008. Causes and consequences of plant-associated 678 biofilms. FEMS Microbiol Ecol 64:153-166.

679 Ryder VJ, Chopra I, O’Neill AJ. 2012. Increased mutability of Staphylococci in biofilms as a 680 consequence of oxidative stress. PLoS One 7:e47695.

681 Saint-Ruf C, Garfa-Traoré M, Collin V, Cordier C, Franceschi C, Matic I. 2014. Massive 682 diversification in aging colonies of Escherichia coli. J Bacteriol 196:3059-3073.

683 Schellhorn HE, Stones VL. 1992. Regulation of katF and katE in Escherichia coli K-12 by 684 weak acids. J Bacteriol 174:4769-4776.

685 Schembri M, Kjaergaard K, Klemm P. 2003. Global gene expression in Escherichia coli 686 biofilms. Mol Microbiol 48:253-267.

687 Seaver LC, Imlay JA. 2004. Are respiratory enzymes the primary sources of intracellular 688 hydrogen peroxide? J Biol Chem 279:48742-48750. 
689 Seib KL, Wu HJ, Srikhanta YN, Edwards JL, Falsetta ML, Hamilton AJ, Maguire TL, 690 Grimmond SM, Apicella MA, McEwan AG, Jennings MP. 2007. Characterization of the 
713 Thompson JR, Rivera HE, Closek CJ, Medina M. 2015. Microbes in the coral holobiont: 714 partners through evolution, development, and ecological interactions. Front Cell Infect 715 Microbiol 4:1-20.Tomida H, Yasufuku T, Fujii T, Kondo Y, Kai T, Anraku M. 2010. 716 Polysaccharides as potential antioxidative compounds for extended-release matrix tablets. 717 Carbohydrate Res 345:82-86.

718 Tsuneda S, Aikawa H, Hayashi H, Yuasa A, Hirata A. 2003. Extracellular polymeric 719 substances responsible for bacterial adhesion onto solid surface. FEMS Microbiol Lett $720 \quad 223: 287-292$

721 Van Houdt R, Michiels CW. 2010. Biofilm formation and the food industry, a focus on the 722 bacterial outer surface. J App Microbiol 109:1117-1131.

723 Villa F, Albanese D, Giussani B, Stewart PS, Daffonchio D, Cappitelli F. 2010. Hindering 724 biofilm formation with zosteric acid. Biofouling 26:739-752.

725 Villa F, Pitts B, Stewart PS, Giussani B, Roncoroni S, Albanese D, Giordano C, Tunesi M, 726 Cappitelli F. 2011. Efficacy of zosteric acid sodium salt on the yeast biofilm model Candida 727 albicans. Microb Ecol 62:584-598.

728 Villa F, Borgonovo G, Cappitelli F, Giussani B. 2012a. Sub-lethal concentrations of Muscari 729 comosum bulb extract suppress adhesion and induce detachment of sessile yeast cells 730 Biofouling 28:1107-1117.

731 Villa F, Remelli W, Forlani F, Gambino M, Landini P, Cappitelli F. 2012b. Effects of chronic 732 sub-lethal oxidative stress on biofilm formation by Azotobacter vinelandii. Biofouling $73328: 823-833$.

734 Villa F, Remelli W, Forlani F, Vitali A, Cappitelli F. 2012c. Altered expression level of 735 Escherichia coli proteins in response to treatment with the antifouling agent zosteric acid 736 sodium salt. Environ Microbiol 14:1753-1761. 
Villa F, Cappitelli F. 2013. Plant-derived bioactive compounds at sub-lethal concentrations:

738 towards smart biocide-free antibiofilm strategies. Phytochem Rev 12:245-254.

739 Vlamakis H, Chai Y, Beauregard P, Losick R, Kolter R. 2013. Sticking together: building a 740 biofilm the Bacillus subtilis way. Nat Rev Microbiol 11:157-168.

741 Wahl M, Goecke F, Labes A, Dobretsov S, Weinberger F. 2012. The second skin: ecological 742 role of epibiotic biofilms on marine organisms. Front Microbiol 3:1-21.

743 Walters MC, Roe F, Bugnicourt A, Franklin MJ, Stewart PS. 2003. Contributions of antibiotic 744 penetration, oxygen limitation, and low metabolic activity to tolerance of Pseudomonas 745 aeruginosa biofilms to ciprofloxacin and tobramycin. Antimicrob Agents Chemother 47:317746323.

747 Waters CM, Bassler BL. 2005. Quorum sensing: cell-to-cell communication in bacteria. Ann 748 Rev Cell Develop Biol 21:319-346.

749 Wei Q, Le Minh PN, Dötsch A, Hildebrand F, Panmanee W, Elfarash A, Schulz S, Plaisance 750 S, Charlier D, Hassett D, Haussler S, Cornelis P. 2012. Global regulation of gene expression 751 by OxyR in an important human opportunistic pathogen. Nucl Acids Res 40:4320-4333.

$752 \mathrm{Wu}$ J, Lin X, Xie H. 2008. OxyR is involved in coordinate regulation of expression of fimA 753 and sod genes in Porphyromonas gingivalis. FEMS Microbiology Lett 282:188-195.

754 Wu X, Wang X, Drlica K, Zhao X. 2011. A toxin-antitoxin module in Bacillus subtilis can 755 both mitigate and amplify effects of lethal stress. PLoS One 6:e23909.

756 Wu Y, Vulić M, Keren I, Lewis K. 2012. Role of oxidative stress in persister tolerance. 757 Antimic Agents Chemoth 56:4922-4926.

758 Wu Y, Ding Y, Cohen Y, Cao B. 2015. Elevated level of the second messenger c-di-GMP in 759 Comamonas testosteroni enhances biofilm formation and biofilm-based biodegradation of 3760 chloroaniline. Appl Microbiol Biotechnol 99:1967-1976. 
761 Xie K, Peng H, Hu H, Wang W, Zhang X. 2013. OxyR, an important oxidative stress 762 regulator to phenazines production and hydrogen peroxide resistance in Pseudomonas 763 chlororaphis GP72. Microbiol Res 168:646-653.

764 Zardus JD, Nedved BT, Huang Y, Tran C, Hadfield MG. 2008. Microbial biofilms facilitate 765 adhesion in biofouling invertebrates. Biol Bull 214:91-98.

766 Zhao X, Drlica K. 2014. Reactive oxygen species and the bacterial response to lethal stress. 767 Curr Opin Microbiol 21:1-6.

768 Zheng L, Chen Z, Itzek A, Ashby M, Kreth J. 2011. Catabolite control protein A controls 769 hydrogen peroxide production and cell death in Streptococcus sanguinis. J Bacteriol 193:516770526.

771 Ziegelhoffer EC, Donohue, TJ. 2009. Bacterial responses to photo-oxidative stress. Nat Rev 772 Microbiol 7:856-863.

773 


\section{$774 \quad$ Figure captions}

775 Figure 1. Emerging avenues of research to investigate biofilm response to oxidative stress.

776 Figure 2. Exposure to sub-lethal doses of the ROS producer caused a change in the 777 morphology of the colony biofilm. a) Effect of hydrogen peroxide on Burkholderia 778 thailandensis, b) Effect of phenazine methosulphate (PMS) on Azotobacter vinelandii.

779 Figure 3. Sublethal doses of PMS trigger the accumulation of exopolysaccharides in the 780 matrix of the colony biofilm of Azotobacter vinelandii. Cryosectioning images of untreated 781 (a) and treated (b) mature biofilms: in green, live cells were stained green with Syto9; in red, 782 the polysaccharide component of the EPS matrix was stained with Texas Red-labelled 783 Concanavalin. Scale bar: $100 \mu \mathrm{m}$. 
Figure 1. Emerging avenues of research to investigate biofilm response to oxidative stress. $225 \times 141 \mathrm{~mm}(72 \times 72 \mathrm{DPI})$ 
a)
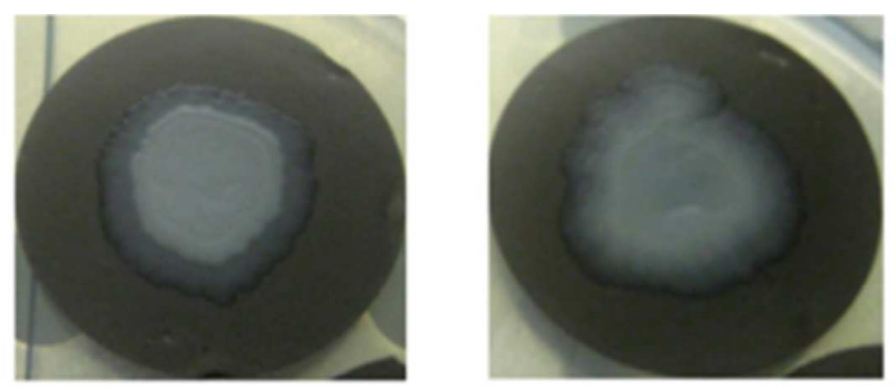

b)
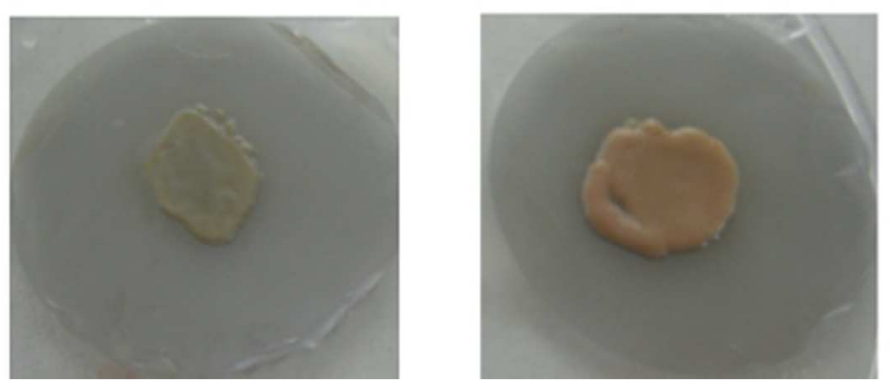

Figure 2. Exposure to sub-lethal doses of the ROS producer caused a change in the morphology of the colony biofilm. a) Effect of hydrogen peroxide on Burkholderia thailandensis, b) Effect of phenazine methosulphate (PMS) on Azotobacter vinelandii. $209 \times 131 \mathrm{~mm}(72 \times 72$ DPI $)$ 
a)
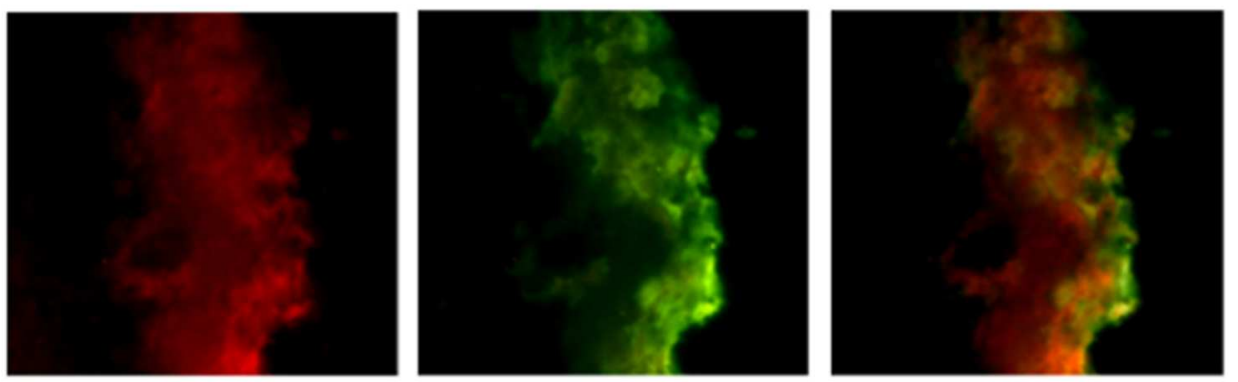

b)
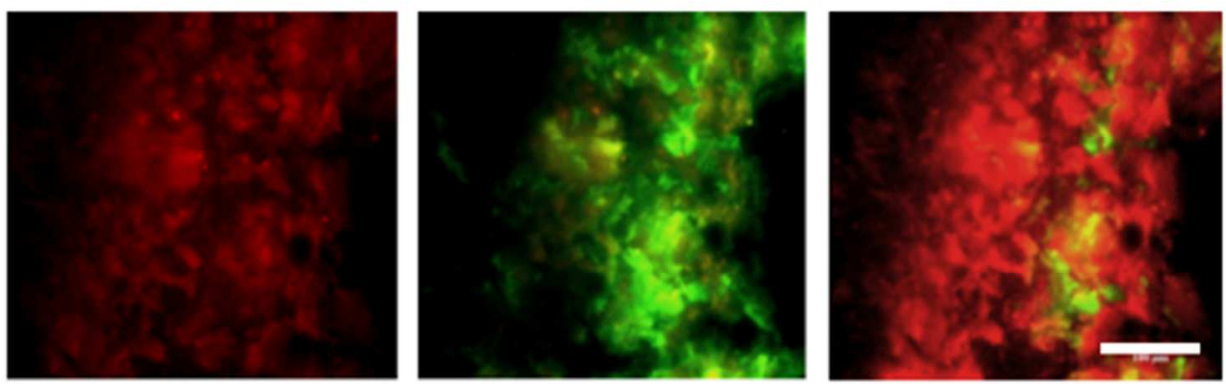

Figure 3. Sublethal doses of PMS trigger the accumulation of exopolysaccharides in the matrix of the colony biofilm of Azotobacter vinelandii. Cryosectioning images of untreated (a) and treated (b) mature biofilms: in green, live cells were stained green with Syto9; in red, the polysaccharide component of the EPS matrix was stained with Texas Red-labelled Concanavalin. Scale bar: $100 \mu \mathrm{m}$. $225 \times 141 \mathrm{~mm}(72 \times 72 \mathrm{DPI})$ 